\title{
Reformulando el museo en el contexto actual de crisis
}

\author{
Susana Solís Zara
}

Resumen: El presente artículo -de opinión personal- atiende a una crítica y análisis del rol del museo de arte contemporáneo en un contexto de crisis económica y de reconfiguración. Donde hemos pasado, a partir el inicio del postmodernismo, del fenómeno "efecto museo" y proliferación memorística -acrecentada en pleno boom económico- a nuevos tiempos de incertidumbre donde muchas instituciones museísticas de nuestro país ven afectadas sus colecciones por los recortes y ajustes presupuestarios de las diferentes Administraciones Públicas (AAPP), aumentando de esta manera el peligro de la defensa del programa y la disminución de la actividad de estos espacios expositivos que, asimismo, sufren modificaciones constantes, que necesitan adaptarse a los nuevos tiempos y a las propuestas emergentes de los artistas.

Contribuiremos -a modo de reflexión- a la discusión introduciendo ciertas cuestiones sobre el tema, cómo el impacto de la actual crisis financiera y recesión económica pone en peligro tanto la supervivencia de muchos centros culturales como la divulgación, educación e investigación de nuestro patrimonio artístico y cultural. Pues aunque no es nuestro fin aportar en este trabajo datos estadísticos ni cuantitativos, si tenemos en cuenta el tipo de titularidad, España cuenta actualmente con más de 1.550 museos y colecciones museográficas, de los cuales el $67,5 \%$ son museos públicos, un $30,4 \%$ son privados y un 2 ' $1 \%$ son de titularidad mixta'.

Palabras claves: museos; crisis; patrimonio artístico y cultural; arquitectura museística; visitantes; contenido y continente; teoría y crítica institucional; turismo cultural.

\section{Reformulando o museu no contexto actual de crise}

Resumo: O presente artigo - de opinião pessoal - apresenta uma crítica e análise sobre o papel do museu de arte contemporânea num contexto de crise económica e de re-configuração. O que se passou, desde o início do post-modernismo, do fenómeno "efeito museu" e da proliferação memorística - acrescentada em pleno boom económico - até aos novos tempos de incerteza onde muitas instituições museológicas do nosso país vêm as suas colecções afectadas pelos cortes e ajustes de budget das diferentes Administrações Públicas (AAPP), aumentando, desta maneira a dificuldade na prossecução do programa e a diminuição da actividade destes espaços expositivos, que assim mesmo, sofrem modificações constantes para adaptar-se aos novos tempos e às propostas emergentes dos artistas.

Em modo de reflexão, contribuiremos para a discussão, introduzindo certas questões sobre o tema, como o impacto da crise actual financeira e a recessão económica colocam em perigo, tanto a sobrevivencia de muitos centros de divulgação, educação e investigação do nosso património artístico e cultural. Ainda que não seja nosso objectivo apresentar, neste trabalho, dados estatísticos nem quantitativos, se considerarmos o tipo de tutela, Espanha conta, actualmente com mais de 1.550 museus e colecções museológicas, dos quais $67,5 \%$ são museus públicos, 30,4\% são privados e 2,1\%, têm uma tutela mista.

Palavras-chave: museus; crise; patrimonio artístico e cultural; arquitectura museológica; visitantes; conteúdo e continente; teoría e crítica institucional; turismo cultural.

\section{Redefining the museum in the context of present crisis}

Abstract: This article presents an analysis and critique -from a personal standpoint- of a contemporary art museum's role in a time of economic crisis and reconfiguration. What's happened since the beginning of postmodernism, the "museum era" and memory proliferation, which increased due to the economic boom, is a new era of uncertainty where many museum institutions of our country and its collections have been 
affected by cuts and the budget adjustments of different Public Administrations. This has put these institutions in danger and decreased activity in these exhibition spaces which are also suffering from constant changes. We must adapt to the new times and to the emerging artists' proposals.

By reflecting we will contribute to the discussion by introducing some questions on the subject, how the impact of the current financial crisis and economic recession endangers both the survival of many cultural centers and research of our artistic and cultural heritage. Although it's not our goal to provide statistical and quantative data, if we consider the type of ownership, Spain currently has over 1,550 museums and museum collections, of which $67.5 \%$ are public museums, $30.4 \%$ are private and $2.1 \%$ are of mixed ownership.

Key words: Museums; crisis; artistic and cultural heritage, museum architecture; visitors, content and continent, theory and institutional critique; cultural tourism.

\section{Introducción}

En el contexto de la sociedad postindustrial, la cultura y el conocimiento toman protagonismo, del mismo modo que la memoria y su recuperación se han convertido en una obsesión global. El concepto de patrimonio cultural ha crecido sin cesar en los últimos tiempos con la aparente intención de dar satisfacción tanto a una sociedad postfordista que demanda "un mayor conocimiento" como a una insistente mirada hacia el pasado. Tal y como advertía el crítico alemán Andreas Huyssen: "Uno de los fenómenos culturales y políticos más sorprendentes de los últimos años es el surgimiento de la memoria como preocupación central de la cultura y la política de las sociedades occidentales" (Huyssen 2002: 23).

Como resultado, cada vez ha sido más habitual la creación y ampliación de nuevos espacios culturales para albergar un determinado patrimonio (material e inmaterial). Incesantemente se han fundado múltiples y distintos tipos de museos, extensiones o renovaciones de antiguos edificios como centros culturales, nuevos espacios con carácter museístico y/o conmemorativos, múltiples (macro) exposiciones, nuevos proyectos artísticos y culturales de digitalización (gracias especialmente a los nuevos mecanismos de producción de imagen, a las nuevas tecnologías de la información y la comunicación -TIC-, así como a la democratización informativa de la redes mediáticas) ${ }^{2}$, y a diversos modelos museológicos y museográficos que plantean un nueva concepción de museo que poco tiene que ver con el tradicional museo-almacén.

Este "efecto museo" y proliferación memorística se ha dado desde la década de los setenta, pero se ha intensificado a partir de los años ochenta, cuando se afianzó la cultura posmoderna del entretenimiento y la industria cultural ${ }^{3}$ de la sociedad postindustrial, coincidiendo a su vez con las estrategias revisionistas de la institución artística y con un crecimiento económico. En especial con el Centro Georges Pompidou de París (1977), pionero en lo que a público masivo se refiere y el que marcará el punto final de los museos del Movimiento Moderno y de partida de la Postmodernidad, cuando se dé con mayor impulso el fenómeno de un considerado aumento de nuevos museos y centros de arte contemporáneo, tanto de nueva planta como de edificios reutilizados para tal fin. Mas en el caso de España, hasta la llegada de la democracia no se catalizarán nuevos movimientos, por tanto este fenómeno se iniciará con bastante retraso incorporándose a finales de los años ochenta, siendo el punto de partida la creación en 1986 del Centro de Arte Reina Sofía 4 .

De modo que aquellas formulaciones de nihilismo "museal" y del arte institucionalizado levantadas sobre todo en los años sesenta y setenta por parte de distintos artistas y pensadores (ceñidos al debate sobre la muerte de Dios, el Ser y el Arte $)^{5}$, paradójicamente desembocó en una progresiva 
expansión museística, cobrando el museo todo su protagonismo y su monopolio en el discurso artístico dominante y en la difusión del arte en una vitalidad nunca vista hasta ahora, al igual que la exitosa proliferación de centros artísticos, galerías de arte y (macro) exposiciones.

Este fenómeno, desde las dos últimas décadas del siglo XX y principios del siglo XXI, ha adquirido tal dimensión que merece cierta reflexión o comprensión y un deseo de interpretación que, en "nuestro" caso, parte del asombro que despertó el macroespectáculo de la museomanía arquitectónica que se ha estado rivalizando principalmente entre los museos y centros de arte contemporáneo. Además, este interés por el museo nace de una serie de preguntas que, como artista y consumidora interesada en el hecho expositivo, me hago acerca de las prácticas de exhibición dentro y fuera de los museos y en torno a los espacios de discusión sobre las prácticas artísticas e institucionales.

Si bien, la madre institucional museística una vez más se encuentra en plena crisis de identidad -en un contexto de profunda crisis económica, financiera y política-, en busca de una necesaria reformulación de su concepción desde su uso, según su finalidad, acorde a los nuevos tiempos. Del mismo modo que la exposición entendida como dispositivo de presentación artística (y uno de los elementos primordiales de la articulación discursiva del museo) por los contenidos con los que ella trabaja en el arte contemporáneo, entre otras causas, necesita de una definición puesta permanentemente en crisis para evitar que se transforme en un intocable instrumento superado (Manen 2012: 12).

\section{Objetivos, relevancia de la investigación y metodología}

El objetivo principal de este estudio abierto, es la inducción a una profunda reflexión y a un debate de múltiples interrogantes que traza la posición existente del museo postmoderno en el contexto de crisis actual, profundizando en el conocimiento de nuevos planteamientos y usos del museo a través de distintos períodos y ejemplos internacionales (muy distintos en relación con aquellas que ha ido asumiendo el museo tradicional desde sus orígenes: pasando de ser simples almacenes, contenedores de tesoros merecedores de fervor, a reivindicarles una dinámica viva, mudable y renovadora). Teniendo también en cuenta la presentación expositiva -como formato estrella- del arte contemporáneo. Esbozando cuáles son algunos de los mecanismos y relaciones de poder y control de las instituciones museísticas, donde se revisan algunas de las propuestas e ideas que plantean distintos autores desde la teoría y la crítica institucional, donde se encuentran muchas preguntas, que más que responder, me interesa plantear.

Nunca como hasta este momento había sido tan cuestionado el papel del museo como institución cultural, hasta el punto de que en numerosas ocasiones se ha hablado de una "muerte del museo", en concreto de los museos de arte contemporáneo. Pero a pesar de que el museo es una "institución en crisis" tampoco antes había despertado tanto interés como también demuestra la reciente numerosa producción bibliográfica museística -de la que haremos un gran uso en nuestra metodología de trabajo- a la vez que se ha convertido en un centro de mira de numerosos historiadores, teóricos y artistas, como paradigma de la cultura contemporánea, deslizando a la obra de arte a un segundo plano.

La relevancia de este trabajo pone también en cuestión el antecedente que originó la inquietud por el problema que se desea analizar: la posición artística del edificio-museo, pues el interés por crear un diseño espectacular ha supuesto el riesgo de que la arquitectura museística arrebate la 
importancia a las obras exhibidas. Tal y como puso de moda el Guggenheim de Bilbao, inaugurado con rotundo éxito en 1997, como paradigma de la cultura convertida en instrumento de consumo pero también de revitalización urbana y económica (Guasch y Zulaika 2007: 13; Zulaika 1997). Cuestión que, interrogada en multitud de ocasiones (especialmente en foros, conferencias y publicaciones especializadas) los diferentes y diversos aspectos de la nueva museografía, es pertinente analizar ya que está profundamente relacionado con la crisis de estas instituciones culturales.

Por otra parte, los museos se han convertido a finales del siglo pasado en uno de los principales referentes culturales, tendencia que mueve a miles de turistas todos los años, pero esta nueva situación no está exenta de una serie de problemas que trataremos también de prestarle atención y que empezaron a examinarse en el S. XX.

Si bien, no es menos cierto que a día de hoy este tipo de construcciones se ha visto aminorado por la recesión económica, puesto que una de las primeras consecuencias de la crisis en los museos tiene que ver con los proyectos de construcción y renovación, muchos proyectos importantes han sido aplazados o directamente abandonados, y otros ya construidos han sido cerrados. Este nuevo fenómeno, se presta a un significativo análisis y valoración, en el que adoptaré una metodología de trabajo de carácter reflexiva y crítica -desde una sensibilización con el asunto a partir de la observación y experiencia en la visita a estos espacios expositivos, enriquecida con el estudio de la teoría y la crítica institucional, la consulta de fuentes bibliográficas en materia museística y publicaciones de revistas especializadas, investigaciones, páginas web, prensa, etc., con la intención de aportar nuevas preguntas y respuestas a este tema vigente de existente discusión, para que este artículo teórico no constituya un punto final de este trabajo, sino una puerta abierta hacia la prolongación de este estudio u otro.

\section{Resultados y discusión}

En nuestra sociedad occidental, mediatizada y consumista, calificada por algunos de postmoderna y neobarroca, el Museo a pesar de ser una institución primordial en el ámbito cultural y patrimonial, es hoy día algo más que un espacio arquitectónico -apropiado- para la conservación y contemplación de obras que han sido socialmente consideradas como artísticas, se ha convertido con mayor asiduidad en objeto y objetivo público de deseo que ha hecho acrecentar la aparición de nuevos planteamientos y usos de éste muy distintos en relación con aquellos que ha ido asumiendo el museo tradicional desde sus orígenes.

No cabe duda que ha perdido vigor en la sutil definición y análisis del filósofo-sociólogo alemán Theodor W. Adorno, dado en la década de los sesenta, al equiparar museo con mausoleo:

"La palabra alemana museal tiene connotaciones desagradables. Describe objetos con los que el observador ya no tiene una relación vital y que están en proceso de extinción. Deben su preservación más al respeto histórico que a las necesidades del presente. Museo y mausoleo son palabras conectadas por algo más que la asociación fonética. Los museos son los sepulcros familiares de las obras de arte [...]" (Adorno 1962: 187).

Efectivamente, el museo es un lugar donde se transforma la percepción de las obras, son mucho más que refugios neutros para el arte. Sin embargo, hace ya tiempo que dejó atrás la función de dar sólo cuidado a las colecciones particulares y a programas determinados, la superación del modelo de museo como palacio, como galería o como templo, es a día de hoy una evidencia, ya no 
es esencialmente un tesoro de colecciones de objetos culturales. Inclusive numerosos son los museos que han sido creados sin una colección permanente, fenómeno que ha hecho valorizar todavía más el objeto arquitectónico -exhibido como continente y contenido- siendo la única obra de arte permanente aunque no inalterable por la crecida de ampliaciones, extensiones y remodelaciones del edificio. Pasando de un aparente contenedor neutro a un objeto artístico destacado de la exposición y, en consecuencia, transformándose estas "nuevas catedrales" de nuestro tiempo -nada exentas de espectáculo- en uno de los espacios más relevantes de promoción urbana, de peregrinación del turismo y en lugar de atracción para el consumo de masa [figura 1].

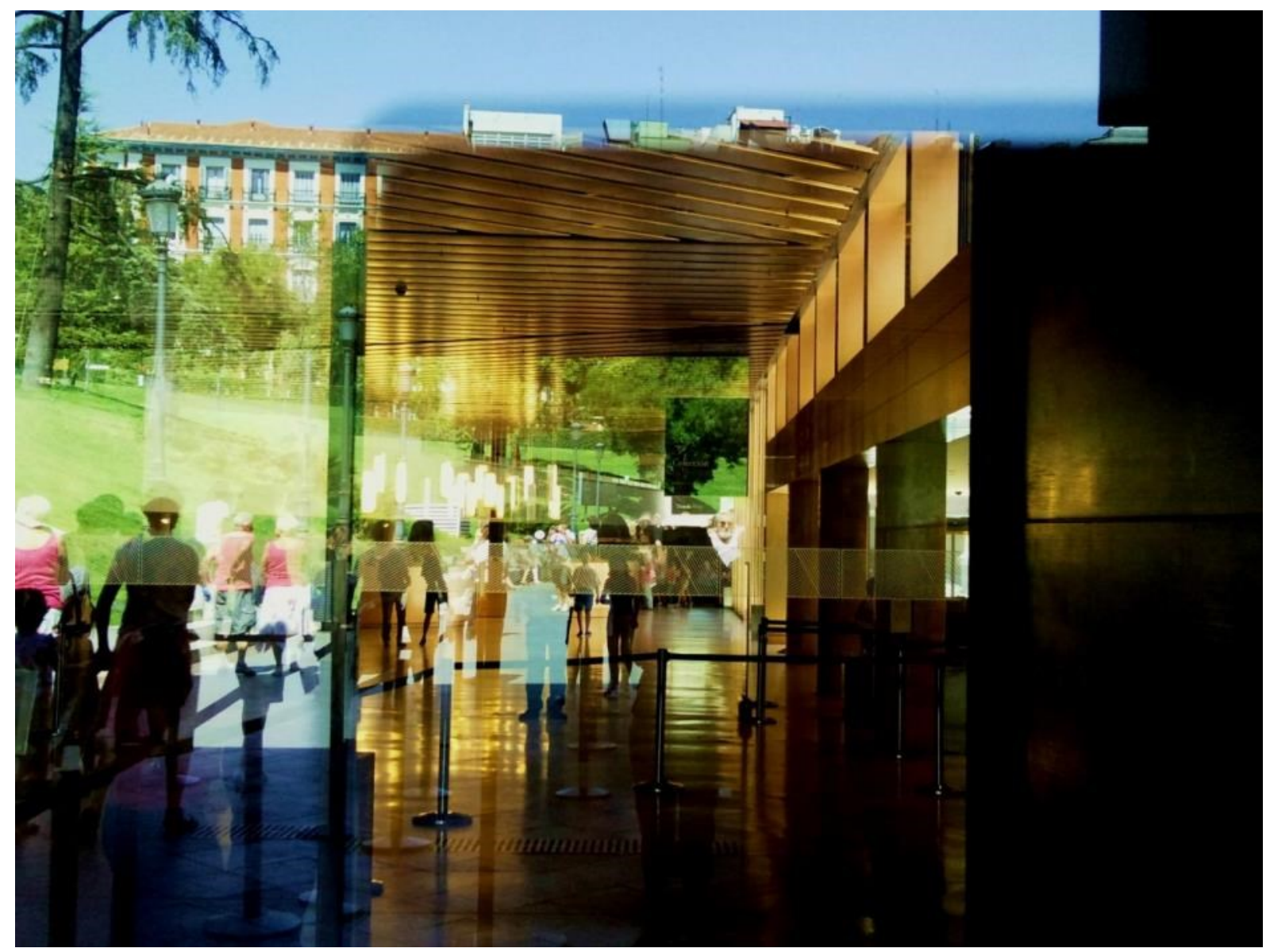

Figura 1. Imagen de visitantes en el Museo del Prado (Madrid). Detalle de la reciente ampliación del arquitecto R. Moneo (2007). @Susana Solís Zara.

Esta actual "embriaguez museística", en el que hemos pasado del modelo de museo-almacén, al museo fábrica (o laboratorio) y en los últimos años al tipo de museo seductor y espectacular, confirma que "la ciudad postmoderna tiene como emergencia a los museos como monumentos de la economía y de la movilidad social" (Amendola 2000: 183-209), precediendo a estos edificios la atracción de numerosos medios de comunicación y largas colas aglomeradas de un amplio público, mientras que el objeto-museo se ha dispuesto -como un gran centro comercial- a ser consumido debido principalmente a un gran despliegue creativo de sus arquitectos donde "el edificio [museo] debe ser tan personal en su formulación como el lienzo del pintor o el boceto de 
un dibujante", según sostiene el artista y critico Douglas Davis (Davis 1990: 16).

Si el MOMA de Nueva York (fundado en 1929 y construida su nueva sede con arquitectura moderna en 1939) constituyó un nuevo paradigma museístico en la modernidad sirviendo como modelo internacional (con su supuesta pulcritud estética e ideológica del White Cube) (O'Doherty 2011), el Guggenheim neoyorkino (1959) y principalmente la creación del Centro Pompidou de París marcarían un hito a partir del cual todo nuevo museo debía de contar con un peculiar edificio para la recepción de un público masivo. A partir de aquí fue el instante de protagonistas como el espectacular Guggenheim de Bilbao (1997) -uno de los primeros museos que Rosalind Krauss denominó "tardocapitalista"-6 y del poderoso Tate Modern londinense (2000), que a su vez serían rápidamente ensombrecidos por otros ejemplos como fue la ampliación del MOMA en 2004 o la creación de museos de contenido histórico como la extensión del Museo Judío de Berlín (2001), un museo didáctico centrado en una sola obra que es, a su vez, el propio museo, definiéndose efectivamente el contenido a través del contenedor (Montaner 2003).

En las tres últimas décadas la motivación económica y política influyó en crear estos competitivos museos como productos comerciales vinculados al modelo tardocapitalista, influidos además por las medias y por la vertiginosa competición en la que se han desarrollado las ciudades para exhibir uno de estos destacados símbolos y monumentos en la nueva escena urbana. Museos de autor que se han transformado en verdaderos iconos hedonistas de la ciudad postmoderna, buscando afianzar su propia personalidad mediante estos imanes turísticos, estableciendo de esta manera una nueva "cultura artística" y cuestionándonos si estos museos han ayudado realmente a propagar un mayor conocimiento de cultura artística en el turismo, o han incentivado simplemente el "yo estuve allí" y, por tanto, ha convergido a un "turismo cultural" perjudicial para la cultura.

Como consecuencia, el espectáculo de la arquitectura (museística) como imán de sustanciales audiencias, junto con las pautas que promueven el negocio del ocio y el turismo, pasó a convertir estos espacios culturales en parques temáticos de atracción turística. Positivo, en el sentido de que personas que nunca antes se habían acercado a un museo se aproximan ahora a él, atraídas sobre todo por el marketing de la arquitectura-icono. Por el contrario, la posición negativa es que los "museos-espéctáculo" (con firma Pritzker) han estado restándole valía al tradicional significado del museo; que es de proteger, coleccionar y exponer, ya que según los defensores del "museo tradicional" opinan que verdaderamente lo que diferencia a un museo es la relación entre varias dimensiones: como la parte formal del edificio, objetos a exponer y colección. Lo cierto es que estos "museos estrellas" han desvinculado el edificio del contenido, adquiriendo el continente todo el protagonismo como auténtica pieza artística en sí misma (Giebelhausen 2011), e incentivando al público la peregrinación al edificio el déjà vu. Frente a esta práctica contemporánea, ha estado intentando subsistir el museo "súper-funcional", el cual no tiene un gran envoltorio arquitectural pero si, en muchos casos, una atractiva política cultural.

En el contexto actual de profunda crisis económica y política en toda Europa, pero especialmente en algunos países del sur como España, ahora se observa -mejor que nunca- el sin sentido de esa vía de "espectacularización" mediática del arte de los últimos años, que ha desembocado en una redundancia del mismo y, por consiguiente, en numerosos espacios vacíos sin actividad ni continuidad alguna. Nos hemos visto envueltos, a principios del siglo XXI, en una burbuja de museos difícilmente sostenible. Viéndose afectada sobre todo en aquellos edificios museísticos de formas espectaculares realizadas por arquitectos de renombre, fuertemente criticados por su "falta o exceso de finalidad", como han sido los megacentros culturales del Centro de Niemeyer (en Aviles) y la Ciudad de la Cultura de Santiago de Compostela. 
La crisis actual del museo (de arte contemporáneo) está íntimamente ligada a esa sobresaturación a modo de "efecto Guggenheim" en la que, en tiempos de bonanza económica -época de despilfarro y malversación política y financiera- se ha visto sumergida toda comunidad y ciudad, dando paso a una nueva generación de museos construidos con un interés de revitalización urbana y especulación inmobiliaria y, por tanto, más político, turístico y económico que por incrementar proyectos artísticos y culturales de un verdadero interés, garantizado por programas de una función clara y con vista de prolongación asegurada. ${ }^{7}$ El carácter que les unía a la mayoría de ellos ha sido su espectacular arquitectura, diseñado por un arquitecto de prestigio, para establecer el contenedor como la imagen hegemónica del museo y no la de su contenido [figura 2].

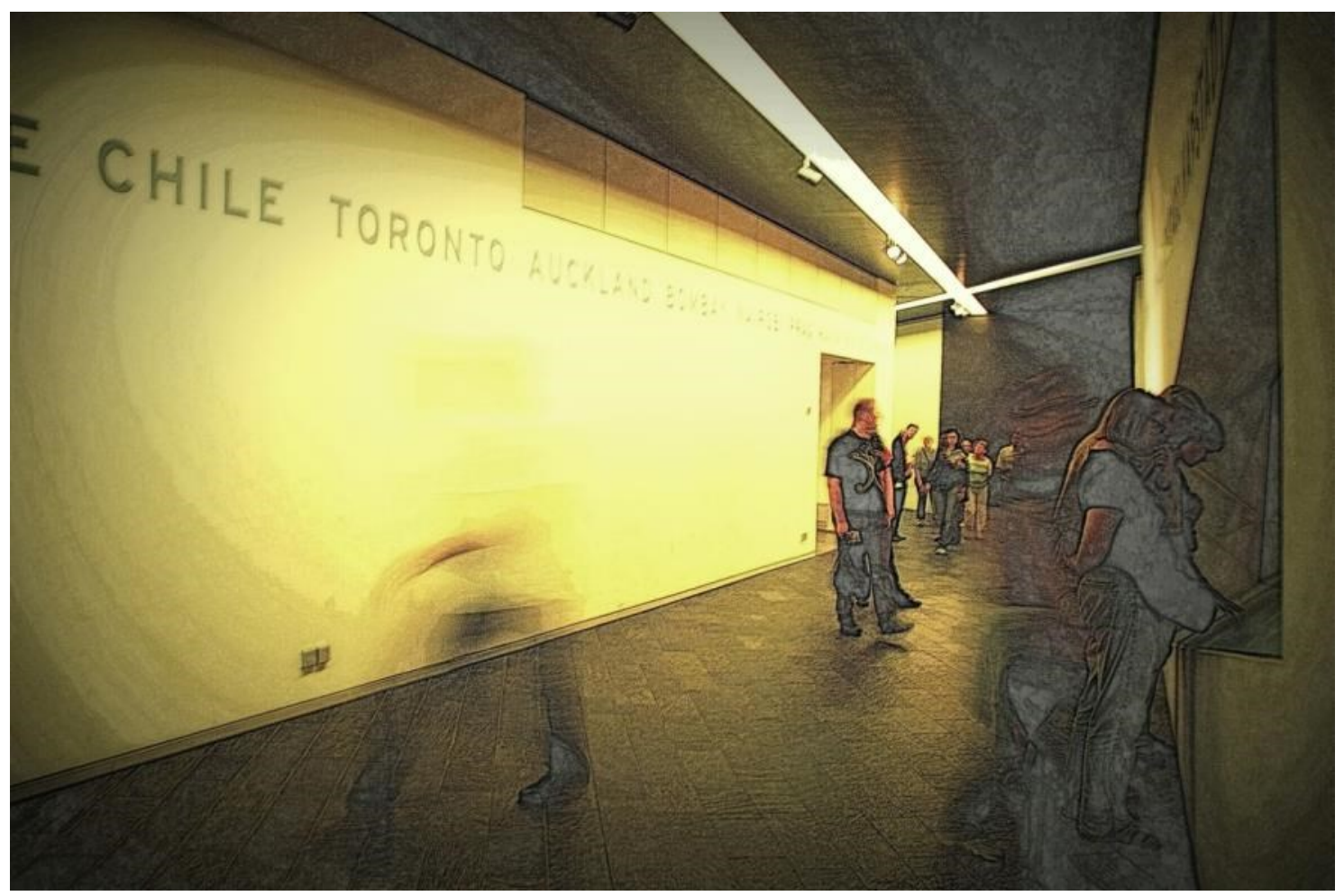

Figura 2. Detalle del Museo Judío de Berlín (2001) diseñado por el arquitecto D. Libeskind. Al igual que el Guggenheim de Bilbao, se ha convertido por su llamativa arquitectura deconstructivista en uno de los edificios más célebres internacionalmente. @Susana Solís Zara.

Definitivamente, el ciclo de crecimiento se cierra con una crisis financiera que pone en duda la supervivencia de muchos centros culturales y sacude el mapa apenas definido de un país puesto al día en estructuras y contenidos artísticos ${ }^{8}$.

En estos tiempos de incertidumbre muchas instituciones museísticas, en las cuales sus estrategias para la captación de visitantes se basan en el atractivo de las colecciones y no en operaciones de marketing (que pasan por la arquitectura icono y aquellas pautas que movilizan el negocio del ocio y el turismo), ven afectadas sus colecciones a causa de los recortes presupuestarios para la adquisición de obras de arte, situación que desafortunadamente conlleva no poder ampliar las colecciones para poder profundizar en este tipo de patrimonio que permitiría enriquecer el conocimiento de los ciudadanos y visitantes. La escasez de grandes colecciones conlleva la 
amenaza de no poder recuperar nuestra memoria histórica, como recientemente señalaba el director del Museo Nacional Centro de Arte Reina Sofía (MNCARS) Manuel Borja-Villel:

"Los huecos en una colección constituyen una especie de vacío en nuestra historia, tanto en lo que respecta a la nueva producción como en lo que se refiere al arte del pasado inmediato. Si los museos son repositorios de la memoria, nuestro país corre el riesgo de la amnesia" (Villel 2012: En línea).

A estas cuestiones se le suma el agravante de que España se ha convertido en el país de la eurozona que grava con el IVA más alto $(21 \%)$ a los productos culturales (aplicado a las artes plásticas, la música, el cine y las artes escénicas), unido a los recortes y ajustes presupuestarios de las AAPP, una medida perjudicial puesto que, sustentada en una consideración errónea de las artes como mero espectáculo, aumenta el peligro de la disminución de recursos, de actividades y de la defensa del programa de los museos y centros de arte contemporáneo, ya que nos guste o no los criterios económicos suelen ser el elemento más decisivo en la definición de la institución y lo que permite que el sistema cultural (con sus diferentes agentes: creadores, comisarios, galerías, etc.) no se debilite.

Mientras tanto, los poderes políticos y económicos han llegado a aportar unos descomunales presupuestos para la creación de estas nuevas catedrales, con la intención de recibir rentabilidad económica y, tal vez, un mayor número de votos por parte de los ciudadanos. Sin lugar a dudas la especulación en el mundo del arte no sólo se da en las obras y en los artistas, sino también en los espacios expositivos". Todo ello ha sido confirmado con el "reventón" de la reciente burbuja, con el cierre de diferentes centros de arte y otras instituciones culturales. Según lo dicho, debemos preguntarnos si el arte contemporáneo, concretamente en España, realmente ha gozado de salud democrática a lo largo de estos últimos años ${ }^{10}$.

Pero no sólo el museo de arte contemporáneo vive un momento de "crisis" de identidad y de reflexión actual, también las galerías de arte contemporáneo, las macro-exposiciones y el formato expositivo tradicional -entendido como un lugar en eterno presente, sin aparente actividad alguna a excepción del día de la inauguración- se encuentran en un estado de reformulación de su concepción y su finalidad acorde a los nuevos tiempos, en la búsqueda de nuevas definiciones y usos adaptables a las propuestas del arte emergente. (Manen 2012: 100). Por tanto, precisamos de otros modelos de presentación y comunicación expositiva para hacer partícipe al espectador frecuentemente distante y en un rol pasivo- para un consumo autónomo y comprometido de los contenidos de la misma, planteándose la incorporación de otros eventos, tiempos, ritmos y nuevos formatos expositivos que generan nuevas formas de análisis crítico del arte.

Al respecto, proyectos de gran envergadura estructural (como es la elección de edificios históricos y naves industriales rehabilitados como centros culturales o construcciones de nueva planta), planteados desde nuevas fórmulas de gestión y para la difusión de nuevas prácticas artísticas contemporáneas están ganando terreno, se presentan partiendo de estructuras híbridas donde tienen lugar a su vez distintos espacios para actividades muy variadas (artes plásticas y audiovisuales, danza, teatro, exposiciones, talleres y conferencias, salas de producción, espacios educativos, etc.), son los que proyectan el Palais de Tokyo o la Le 104 (ambos en París) -siendo el primero, el iniciado en las prácticas artísticas relacionales (Bourriaud 2008)-, u otros centros europeos de similares actitudes (o modos) como son Radialsystem (Berlín) y Zone Attive (Roma), o centros norteamericanos como el Whitney Museum o el Moma Ps1 de Nueva York, y a lo que nuestro modelo más cercano puede ser el Matadero de Madrid, la Laboral de Gijón o la Tabacalera 
de San Sebastián. Son entendidos como nuevos centros de arte contemporáneo de carácter interdisciplinar y dinámico, donde suceden constantemente eventos y actividades, que necesitan de un nuevo ritmo para su funcionamiento. Partiendo además de la idea de lugar de encuentro, de "presentación", de "producción" y "creación" (espacios de investigación artística y residencia para artistas y curadores), son nuevos formatos heterogéneos que comparten lugar en el mismo edificio, con cierta voluntad educativa y popular, e impulsando para ello lo local (e intensificando de igual modo las relaciones entre lo local y lo global) y a un visitante más activo y participativo (Manen 2012).

Esta es quizás hoy día la tipología más cercana de espacio físico para los museos y nuevos centros culturales. Si bien, muchos museos de arte contemporáneo han experimentando una transformación hacia el denominado "centro de arte", propuesto para albergar múltiples actividades más allá incluso de las meramente expositivas y didácticas: marketing, shopping, turismo y estadísticas son los puntos de maniobra para su supervivencia. Para ello se requiere de un giro radical en los contenidos de los museos que tiendan a la incorporación de otras disciplinas, pues no hay que olvidar que hoy casi todo es multi e interdisciplinar, sobre todo en la creación de las artes plásticas y visuales. Concretamente en España cada vez son más los nuevos museos que van surgiendo, en la línea del Musac de León (2005) ${ }^{11}$, que se definen como centros activos de exposiciones de arte contemporáneo y un espacio compartido en el que se despliegan un gran número de actividades multidisciplinares, teniendo como precedente y modelo más cercano el Centro de Cultura Contemporánea de Barcelona (CCCB), inaugurado en 1994 (Carrillo 2008).

Otras instituciones culturales han apostado en los últimos años por tomar como marco de actuación la propia crisis de la institución, agudizada por los actuales recortes presupuestarios en la asignación pública, como es el caso del Museo Nacional Centro de Arte Reina Sofía (MNCARS), tanto en lo referente a la remodelación de la colección del propio museo (llevada a cabo en 2009), como en los proyectos colaborativos puestos en marcha recientemente -con diversos movimientos y colectivos sociales alternativos, independientes y que están basados en la autogestión, de distintos puntos del territorio español- en los que se negocia su tradicional autoridad cultural con otros agentes no institucionalizados pero en los que se reconoce una voluntad instituyente, como es el proceso relacional -cultural y político- que se está llevando desde enero de 2011 entre el Museo Reina Sofía y la Fundación de los Comunes (Carrillo 2012).

Ahora bien, la crisis económica ha inducido a que muchas de estas instituciones artísticas organicen menos exposiciones, fomentando, en consecuencia, las exposiciones de larga duración. Problemática que, por un lado, conlleva una menor demanda de trabajo de profesionales y, por otra parte, plantea qué está legitimando la institución que la presenta, ¿tal vez la arquitectura del museo y su arquitecto (como artista) o bien el comisario que ha llevado a cabo la misma? Las mega-exposiciones están en el punto de mira crítico, ya que conviene más desarrollar exposiciones pequeñas de un mes de duración que promuevan también a artistas locales, teniendo en cuenta la identidad de cada espacio, que aquellas macro-exposiciones, como son las bienales planteadas desde la idea de "continente"12.

En definitiva, las nuevas instituciones artísticas han de impulsar espacios de carácter dinámico, transdisciplinar y activo, enfocados a la producción, investigación, formación, gestión y difusión de la creación artística contemporánea. Lo que conlleva todo ello un distanciamiento de la pulcritud del White Cube y una nueva definición de lo institucional [figura 3]. 


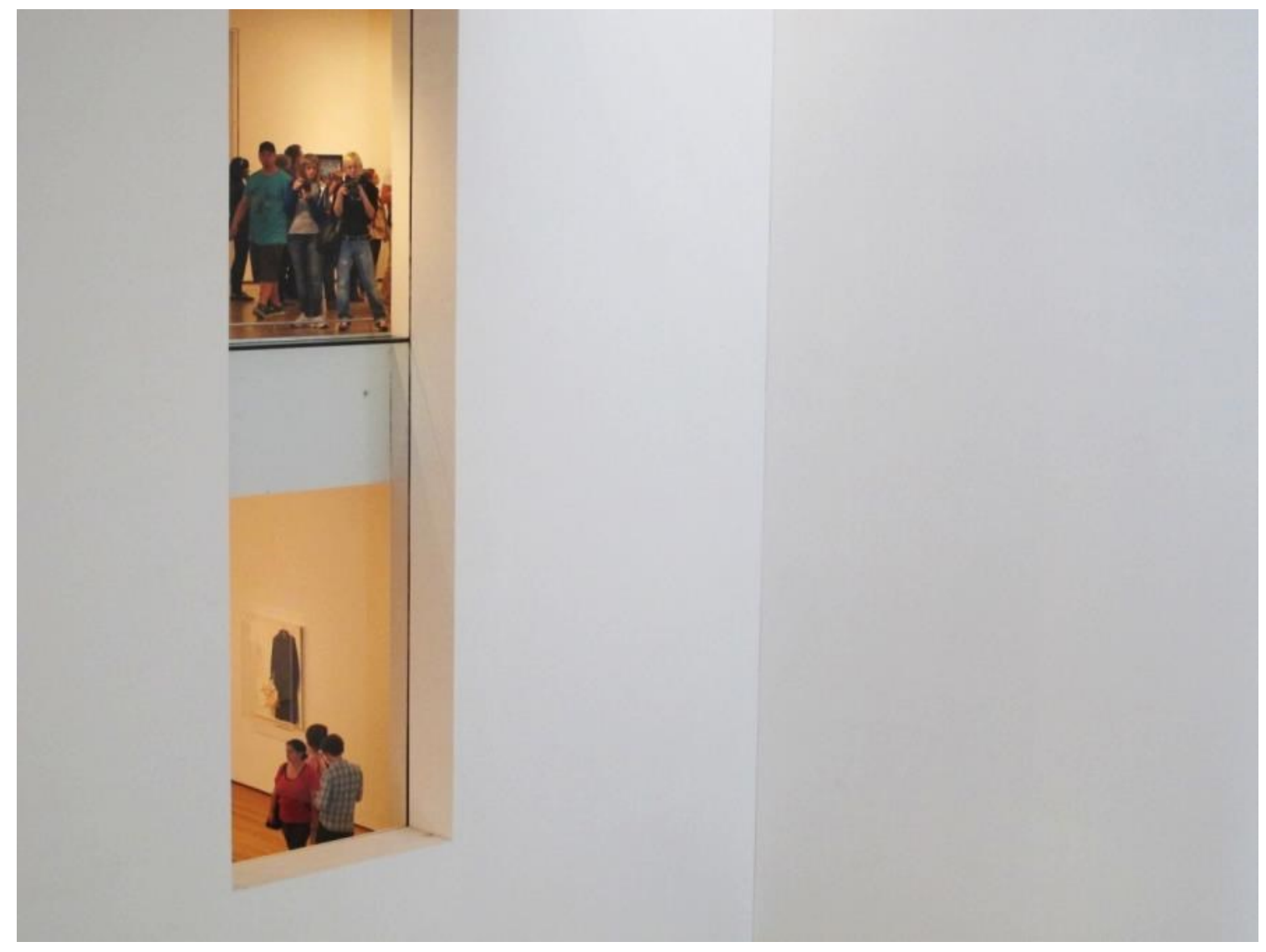

Figura 3. Detalle de la estética White Cube del Museo de Arte Moderno (MOMA) de Nueva York. OSusana Solís Zara.

En esta transformación una figura destacada que ha conllevado la misma ha sido el comisario (curador o curator) como mediador cultural entre las instituciones, el público y el artista. Curiosamente, al igual que comenzaba a cobrar un gran protagonismo los "museos de firma", la figura del comisario iniciaba también su próspera e influyente andadura a partir de los años setenta, reivindicando al arte conceptual y a los intentos de ruptura con los formatos tradicionales y con el desarrollo de un mercado de arte que diera cobijo a las nuevas prácticas artísticas y curatoriales (Guasch 2009). Principalmente gracias a los avances que realizó Harald Szeemann en el año 1969 con la exposición When Attitudes Become Form ("Cuando las actitudes devienen forma") y en 1972 en la Documenta $V$ de Kassel ${ }^{13}$. Ambas exposiciones lograron establecerse como paradigmas de una nueva forma de entender las exposiciones y la figura del comisario, pasando desde entonces por ciclos que define Beatriz Espejo: "De nacimiento en los 70, de gloria en los 80, de boom en los 90, de sobresaturación en los 2000 y, ahora mismo, de replanteamiento" (Espejo 2012: En línea).

Cabe por tanto también cuestionarse si tras la apariencia transgresora de ciertas prácticas curatoriales -frente al criterio taxonómico del museo- se esconde una estrategia de poder que convierte al comisario en autor, en el nuevo "legitimador de modas" y, en consecuencia, creador de cánones que son al fin y al cabo tan parciales y subjetivos como aquellos a los que tratan suplantar, pues sin lugar a dudas el comisario de arte contemporáneo es a día de hoy la figura clave que construye los recorridos y discursos en las instituciones artísticas. (Meijers 1996). 
Ante ello se sigue haciendo necesaria la crítica al discurso oficial de las instituciones y sus jerarquías. La figura del comisario requeriría de una investigación exhaustiva sobre su papel, función y los destacados dispositivos expositivos (o displays) que en muchas ocasiones han cobrado mayor atención que el propio discurso artístico de las obras expuestas (Badia 2011. En línea). Es decir, aún falta una verdadera investigación sobre la importancia de su rol como agente imprescindible en la dinamización y visibilización de los nuevos movimientos artísticos, como en su disposición de funcionamiento y si efectivamente es un intermediario necesario -principalmente en su rol de crítico- para el conocimiento del arte, o simplemente una manera más, al igual que la genialidad de los arquitectos, de seguir alimentando el poder y el control del sistema institucional, eclipsando del mismo modo que la espectacularidad arquitectónica y mediática la atención por otras cuestiones.

En este sentido, es difícil ver si realmente ha habido un cambio en el concepto de museo o sólo es una cuestión retórica del discurso de poder simbólico, político y económico, pues la constante evolución de los museos, unido al triunfo proliferante de los destacados displays de comisariado, enreda aún más la enmarañada madeja del concepto y la situación actual de éstos espacios institucionales. No obstante, esperemos que los museos y nuevos centros permitan activar las prácticas creativas actuales en espacios y contextos apropiados para tal fin, integrando espacios educativos, de investigación y creación, respondiendo a mantener un dinamismo en las actividades, con una oferta de programa continúo y estable, ya que son los contenidos los que deben prevalecer por encima del continente.

\section{Conclusiones}

Concluyendo, la crisis económica obliga favorecer una reconfiguración de las instituciones culturales, pero es difícil ver aún cuál será la repercusión de esta crisis en los museos y cómo enfocarán el futuro. Si bien hemos esbozado, entre otras cuestiones, cómo el impacto de la crisis influye en la construcción, renovación y cierre de muchas instituciones; en la financiación de los museos; en la adquisición de nuevas obras para las colecciones así como en el desarrollo de exposiciones temporales. En el caso de la producción de exposiciones itinerantes, como se necesita invertir grandes presupuestos, los museos cada vez más suelen retrasar la realización de nuevas exposiciones temporales y a mantener las exposiciones permanentes, cuestión que, a mi entender, puede dar pie a una nueva relevancia del concepto museo-almacén, a pesar de que las investigaciones muestran que la multiplicación de exposiciones temporales favorece el aumento de la frecuentación de los museos, situación que indudablemente también beneficia económicamente a dichas instituciones.

Pero, del mismo modo que no podemos dar por sentado como resultado de calidad el éxito expansivo de museos y centros de arte contemporáneo de manera masiva e inminente en continuo crecimiento -aunque a día de hoy en menor grado desde que estalló la crisis-, tampoco podemos dejarnos llevar por las cifras abrumadoras de audiencia que reciben las grandes instituciones artísticas y que en algunos casos, a pesar de la recesión económica, continúan incrementándose ${ }^{14}$. Es necesario buscar nuevos mecanismos que no sean cuantificables para saber cuál es el impacto o el nivel de conocimiento adquirido por el público tras la visita a un museo o una exposición. El éxito no sólo puede medirse cuantitativamente, porque cantidad no es sinónimo de calidad y equidad, ya que "atraer masificación de visitantes no es el camino para democratizar la cultura", como afirmaba recientemente Jesús Carrillo (investigador de crítica institucional y jefe de Programas Culturales del Museo Nacional Centro de Arte Reina Sofía) ${ }^{15}$. 
Pues a pesar de que los museos se han convertido en potentes industrias capaces de generar una enorme cantidad de dinero para las economías locales (hostelería, restauración, transporte, etc.) y, por tanto, desde el punto de vista económico es beneficiosa para una ciudad, lo cierto es que no podemos dar por concluyente que un museo goce de buena salud por las cuantiosas visitas que recibe al año. Ya que este nuevo rol del museo, como eficaz motor de gran atractivo turístico y desarrollo económico, puede distorsionar la misión y el discurso de las instituciones con respecto a una de sus principales tareas: el museo al servicio de la sociedad y su desarrollo como agente educativo y cultural, según el Consejo Internacional de Museos (ICOM), puesto que "lo que justifica en última instancia la institución de los museos es su compromiso permanente con la educación. La educación es consubstancial a la institución llamada museo" (Ballart 2007: 215-216).

De modo que, con respecto a la subida del IVA cultural al 21\%, el Gobierno Central español debería reflexionar para reformar sus políticas culturales y de austeridad aplicadas al ámbito de la cultura y las artes, porque al fin y al cabo esta subida no sólo afecta al sistema cultural y al desarrollo de la creación, sino también al saber, a la educación, a la innovación y la investigación científica. En tiempos de crisis actuales, la cultura y las artes son de máxima prioridad para la autocrítica y autoestima de una sociedad, la precisamos no sólo porque contribuye a aportar conocimiento, sabiduría y entretenimiento, sino porque además la industria cultural es un gran dispositivo económico del país y si aumentan drásticamente los precios, sin lugar a dudas el consumo de cultura descenderá, entre otras consecuencias dañinas para el futuro del país, puesto que la cultura ayuda también a incrementar por ejemplo la actividad económica en otros sectores (como el turístico y el comercial).

Pero no podemos atender exclusivamente a la espectacularidad y el entretenimiento que conlleva el mercado de las industrias culturales como un medio más de riqueza económica, cayendo en un puro consumo, puesto que ello lleva a una espectacularización y banalización del arte y la cultura, a deteriorar el pensamiento y a una ausencia de reflexión crítica que desembocaría en una sociedad desdichada y anquilosada. El museo contemporáneo ha de transmitir otros valores -sobre todo en plena era vacía según G. Lipovestky- no sólo estéticos, culturales y comerciales, sino fundamentalmente valores éticos y morales ${ }^{16}$ que son necesarios en tiempos de crisis actuales (tanto económica, política y social -que evidencian la falla del sistema- como de pérdida de valores personales y sociales). Precisamos de otras iniciativas artísticas que se ajusten principalmente en el impulso de proyectos más que en los edificios, promoviendo la creación local y el modo en que ésta se expresa, generando actividades paralelas a los proyectos expositivos, para concebir momentos de creación de discurso presente e impulsar las relaciones sociales en contacto cercano y directo, siendo para ello esencial enfocarse exclusivamente en los contenidos (Bourriaud 2008: 6-8).

Además, pese a que el enorme aumento de numerosas exposiciones y otros acontecimientos artísticos que se organizan a diario (dentro y fuera de estos espacios) ha sido un factor destacado para atraer un mayor flujo de personas, es necesario fomentar nuevas iniciativas de educación, ya que esta es clave en la emancipación del individuo y en la creación de un espíritu crítico. Es preciso potenciar tanto un mayor número de actividades artísticas y pedagógicas (performances, workshops, seminarios, cursos, congresos, jornadas, ciclos de vídeo y de cine, visitas guiadas, etc.), en museos y centros de arte contemporáneo, como el desarrollo de la creatividad en los centros educativos: formar a creadores y no solamente a meros consumidores, para adquirir no sólo competencias artísticas y culturales, sino también lingüísticas, sociales y ciudadanas, así como de autonomía e iniciativa personal, entre otras [figura 4]. 
Para ello sería conveniente favorecer la creación de centros culturales y artísticos a modo de museos-escuelas de referencia para la educación artística, especialmente en zonas desfavorecidas ${ }^{17}$, dejando de alimentar el obsoleto concepto de museos-refugios elitistas que son al fin y al cabo asequibles para un público minoritario.

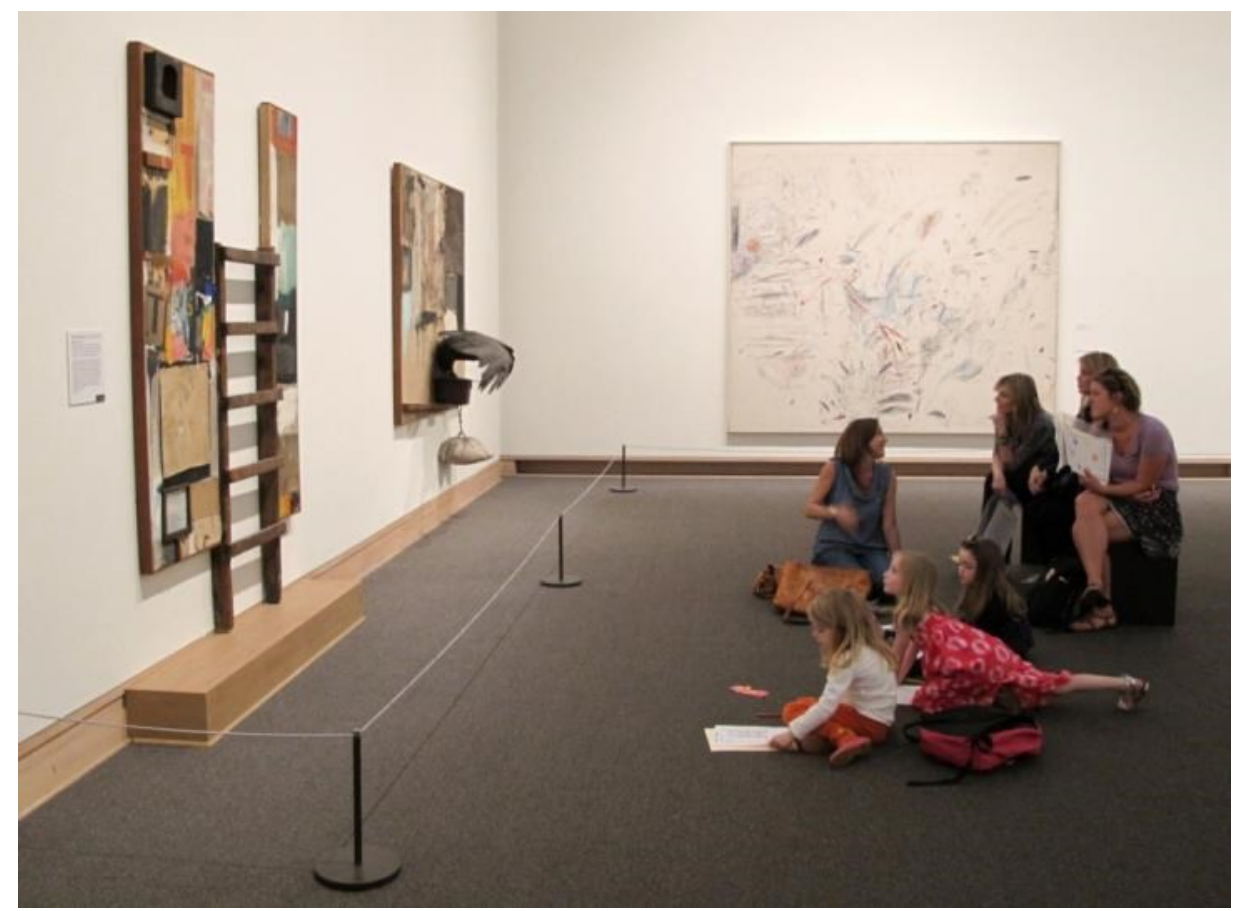

Figura 4. Museo de Arte Moderno (MOMA) de N.Y. CSusana Solís Zara.

Con la intención también de dar respuesta a nuevos retos educativos, estos y otros asuntos relacionados con la institución museística han de debatirse en la enseñanza, ya que están íntimamente ligados con la educación y la cultura, con el aprendizaje artístico-cultural y, por tanto, con la democratización del arte y la cultura. En definitiva, asuntos de poder que están vinculados con lo que se evidencia como conocimiento (o no), con las escalas de jerarquización, influidas de ciertos valores de una clase dominante. ${ }^{18}$ La Universidad especialmente, debe estudiar y analizar esta transformación y evolución, en la que también tiene parte de responsabilidad, con su inestimable y valiosa aportación. Pues si en muchas instituciones culturales se ve cada vez más la necesidad de llevar a cabo programas paralelos a las exposiciones, con actividades educativas, con el fin de facilitar el acceso a la cultura, atender a la diversidad y hacer más partícipe y activo a un amplio y variado público, y si efectivamente algunas de las funciones principales de los museos es precisamente educar, comunicar y ser un productor de sentidos así como un portador visual de la historia (de acuerdo a una mirada y un discurso no neutral), el sistema educativo y la Universidad principalmente tienen ante todas estas cuestiones un importante reto por delante y su contribución es sumamente substancial y necesaria, ya que la educación es además el mejor medio para salvarnos de la crisis actual.

Con dicho fin, la Universidad ha de servir como un foco destacado para la teoría y la crítica institucional (King y Marstine 2006), aproximándonos a la Historia del arte contemporáneo y a la cultura visual de las últimas décadas, debido a los cambios producidos tanto en función del propio 
concepto de arte, como en función de la naturaleza de la institución que lo alberga, lo difunde y lo discute. No nos podemos abstraer de lo que ocurre a nuestro alrededor. El organismo universitario debe participar de manera activa en esta transformación permanente, pues actualmente la existencia del museo en crisis -entendido como plataforma de crítica- se define como un "lugar de encuentro y de debate crítico" (Carrillo 2012), abogando asimismo por la interacción entre culturas, así como entre distintas plataformas artísticas y educativas.

Por consiguiente, la institución museística ha estado y deberá estar en permanente "crisis", ${ }^{19}$ para seguir siendo cuestionada, analizada y sometida a profundas observaciones en sus aspectos básicos (como puede ser su carácter dogmático, de institución de poder y su manipulación en el modo de organizar el conocimiento)(Guasch 2011: 42), con el fin de solventar ciertos malestares para una adaptación favorable a su época, porque al igual que la actividad artística constituye un ejercicio donde las formas, las modalidades y las funciones evolucionan según las épocas y los contextos sociales, y efectivamente no tiene un carácter inmutable, el museo como institución cultural y servicio público ha de estar en constante transformación para adaptarse a las necesidades de los nuevos tiempos, sobre todo según nuestra actual sociedad, tan cambiante y efímera.

No cabe duda que la crisis afecta negativamente al funcionamiento de los museos, pero debemos ser optimistas porque también estimula nuevos desafíos, ya que obliga a replantearse su concepción, su cometido, el desarrollo de sus colecciones y sus estrategias de comunicación. En este sentido, las nuevas tecnologías permitirán a los museos la creación de nuevas formas de conocimiento y de difusión de sus colecciones y archivos, programas expositivos y educativos, además de nuevas formas de trabajo y de relaciones socioculturales mediante la participación en redes sociales, plataformas online y otros nuevos canales que, asimismo, están marcando un cambio de paradigma en la producción, distribución y recepción de la experiencia estética. Por contra no suplirá la asistencia de personas al museo y, en definitiva, las relaciones sociales en un entorno físico "real". Cabe efectivamente cuestionarnos, cuál será el futuro que nos deparará el museo, sobre todo desde el desarrollo de las nuevas tecnologías y plataformas (digitales), ya que es una máquina del tiempo que como identidad cultural y colectiva se ve obligada a una mutación e innovación constante.

\section{NOTAS}

[1] Otro dato a destacar -según la encuesta de 2010 de museos y colecciones museográficas del Ministerio de Educación, Cultura y Deporte- es el número de profesionales que trabajan en estas instituciones: 14.784. De los cuales, el $91 \%$ trabajan en museos de titularidad pública. Datos que, a su vez, han sido publicados recientemente en el Diario El Confidencial. Sobre ello véase: "Los profesionales de los museos dan la voz de alarma sobre su precariedad" (El Confidencial, 26-03-13).

[2] Hoy más que nunca se ha hecho realidad el sueño de André Malraux expresado en su ensayo, sobre un museo de confrontación y de metamorfosis, El Museo Imaginario (1947), el cual se nutre de la "reproducción en serie" de una obra de arte en todas sus formas y formatos. Respecto a una reciente interpretación de ello véase: Rosalind Krauss "Postmodernism's Museum Without Walls" (2005: 241245).

[3] La denominación de "industria cultural" es considerado uno de los primeros conceptos de la teoría crítica sobre la cultura de masas, acuñado en 1944 por los filósofos alemanes Theodor Adorno y Max Horkheimer que lo inscriben en una profunda reflexión sobre el devenir de la cultura en su Dialéctica de la llustración. Fragmentos filosóficos (Adorno y Horkheimer 1944). 
[4] En España existen tres precedentes de centros de arte contemporáneo, según advierte el Historiador y Conservador de Museos José Ramón López Rodríguez en su libro Historia de los museos de Andalucía 1500-2000 (2010: 538): el Centro de Arte Reina Sofía de Madrid, inaugurado en su primera fase en 1986 acogiendo muestras temporales, y que en 1988 pasaría a convertirse en el Museo Nacional Centro de Arte Reina Sofía (MNCARS) tras asumir la colección del Museo de Arte Contemporáneo de Madrid; El Instituto Valenciano de Arte Moderno (IVAM), inaugurado en 1989; y el tercero, el Centro Atlántico de Arte Moderno (CAAM), inaugurado en el mismo año que el IVAM.

[5] El inicio de la segunda mitad del siglo XX es también el momento en el cual el sistema del arte empieza a tambalearse bajo el signo de "la muerte del autor", proclamada por el filósofo y semiólogo francés Roland Barthes en su famoso ensayo -de corte estructuralista- "La muerte del autor" (1968). Además, según los cambios sociales y culturales que se avecinaban en la década de los 60 y 70, una serie de teóricos, intelectuales y artistas ponían en cuestión la validez y los valores del museo moderno (en relación a la "pérdida de la autoría" (institucional) proclamada por Barthes).

Asimismo, una de las críticas más mortíferas será la de Theodor W. Adorno dada en 1962, teniendo en cuenta el pensador alemán las teorías formuladas por Paul Valéry respecto al "museocontenedor", en el sentido de restarle vida propia a las obras exhibidas tales espacios neutros de la modernidad, constituyendo en definitiva una estrategia de poder relacionada con la supremacía del capitalismo y que, por tanto, neutraliza la propia cultura, razón demás por la que Adorno terminó considerando los "museos como mausoleos" y "sepulcros para las obras de arte", en su publicación "Valéry Proust Museum" (1962: 187). Si bien, uno de los autores que mejor narró aquel inminente cuestionamiento, en torno a la supremacía estética e ideológica que "glorificaba" el museo moderno, fue Brian O'Doherty con su publicación "Dentro del Cubo Blanco. La ideología del espacio expositivo" (1976).

Otro texto influyente sobre la crítica al museo, donde se plantea la pérdida del aura (ya preconizada por Walter Benjamin en "La obra de arte en la época de su reproductibilidad técnica", 1936), la pérdida del poder institucional de la autoría y, en definitiva, resalta la "muerte" del museo (a partir del análisis de ciertas obras literarias, filosóficas y artísticas del siglo XX): "Sobre las Ruinas del Museo" (October1980) de D. Crimp, uno de los autores más destacados dentro de la crítica del arte en Norteamérica.

[6] Rosalind Krauss es una de los autores, junto con otros como Carol Duncan y Allan Wallach, pioneros en el análisis del control social ejercido desde el museo y en la denuncia de la conversión del museo en parque temático orientado hacia el espectáculo y el consumo de masas, para Krauss el Guggenheim de Bilbao sería el iniciador de esta tendencia (Krauss 1995: 25).

[7] Tal y como profetizó en 2008 el famoso arquitecto del Guggenheim bilbaino Frank Gehry: "Un edificio puede funcionar muy bien si tiene un programa claro y una función clara. Dicho de otro modo, si es necesario" (Cita extraída en "La burbuja de los museos", El País-Babelia, 14-05-11: 18).

[8] La revista museo.es a finales de 2009 realizó, con motivo de la celebración del III Encuentro Iberoamericano de Museos bajo el lema "Los Museos en un contexto de crisis", una encuesta en torno a la incidencia de la actual crisis en las instituciones museísticas. Las diferentes opiniones recogidas en este artículo han sido publicadas también por Mario Chagas en: "Los museos en el marco de la crisis", revista Museos.es, no 5-6 (2009-10: 86-101). Véase también: Oscar Navarro y Christina Tsagaraki, "Museos en la crisis: una visión desde la museología crítica" Op. Cit. 50-57. Yves Bergeron "Los museos y la crisis. Tendencias en los museos norteamericanos", Op. Cit. 58-67.

[9] Según declaraciones de César Rendueles (adjunto a la dirección del Círculo de Bellas Ates de Madrid): "Incluso para los partidarios de la mercantilización del arte, se ha llegado a momentos de irracionalidad [...]. La rentabilidad del arte, desde los años 70, es puramente especulativa y es una inversión financiera [...]. Ha habido una burbuja de financiación pública, no es razonable que se haya creado un centro de arte público en cada pueblo de 20.000 habitantes" (Rendueles 2012: 5).

[10] En la publicación de la Universidad Internacional de Andalucía (UNIA), 10.000 francos de recompensa. El museo vivo o muerto, Cesar Antonio Molina indicaba en la introducción cómo "El arte 
contemporáneo goza en España de una estupenda salud. Una prueba de ello es el surgimiento en los últimos años de un importante número de museos y centros de arte [...]" (Molina 2009).

[11] "La misión del museo consiste en ser una herramienta fundamental en la creación de sentido colectivo en cuanto al arte y la cultura. La misión actual del museo es vertebrar y reelaborar la idea de museo desde un punto de vista ciudadano cercano al conocimiento y al saber. Así el museo plantea su función dotando de estrategias de actuación y de herramientas criticas de análisis la relación del arte con la sociedad a todos sus niveles en el periodo en el que mueve la Colección del Museo y su programación 1989- actualidad, pero siendo conscientes que la contemporaneidad engloba parte de la historia anterior. [...] La misión del museo con esta Colección, como piedra base, es conservador, difundir, estudiar e hilvanar de una manera amplia y panorámica la importancia del arte en la contemporaneidad en este intervalo de tiempo, bajo premisas conceptuales y sociales que pongan de manifiesto la importancia y la relación del arte en momentos y situaciones sociales, políticas, culturales y estéticas como un verdadero catalizador del momento en que estas obras fueron producidas a través de los diversos discursos generados en la exposiciones de la Colección tanto dentro como fuera del propio museo. [...]" http://musac.es/index.php?secc=1\&subsecc=1.

Por ultimo hay que hacer hincapié en la misión difusora a través de todos los medios y sobretodo de la nuevas tecnologías y plataformas digitales, pero sobre todo en su vertiente educativa y colectiva, puesto que a través de los innumerables jornadas, seminarios, ciclos de cine, y video, performances, talleres de artistas, visitas guiadas, grupos de discusión, etc. que dan a la educación artística y al pensamiento un interés que va mas allá del programa, importancia tanto a los procesos de trabajo en lo expositivo, en el pensamiento como en la educación desde el museo. Por ello la misión fundamental es el acercamiento de todos estos conocimientos y labrar una red de relaciones artísticas la comunidad artística ya sea esta de Castilla y León; de otros ámbitos nacionales o internacionales.

En definitiva el Museo viene a ser como una gran ciudad donde los diferentes agentes, personas que se acercan que la habiten pueden encontrar un lugar de encuentro para la estudio, investigación, discusión, análisis y disfrute del arte y la cultura contemporáneas."

[12] Así lo expresaba también el propio Hans Ulrich Obrist, uno de los comisarios de arte contemporáneo más predominantes en la actualidad y codirector de la Serpentine Gallery londinense, en la entrevista de Elena Vozmediano, "hoy todo es grande, pero creo que el modelo macro-exposición se está hudiendo" (El Cultural, 22-11-2007).

[13] Hans U. Obrist, "When Attitudes Become Form de Harald Szeemann. (Los hitos del arte. 1969: el papel del comisario)", El Cultural, 16-10-2009. Así como la publicación de Hans Ulrich Obrist, A brief history of curating, JRP / Ringier, 2008. [Ed. castellano: Breve historia del comisariado, Madrid, Exit publicaciones, 2010].

[14] Como ejemplo cercano, el Museo Nacional del Prado en 2011 ingresó $11.702 .512 €$, gracias a un notable ascenso de visitantes. Sin embargo, como consecuencia de los recortes de aportación Estatal a la misma, en estos últimos años se ha incrementado el precio de la entrada a un $15 \%$, con el fin de "poder garantizar el cumplimiento de sus funciones", tal y como anunció en El Confidencial el director del museo Miguel Zugaza. Asimismo, debido al declive del turismo, Zugaza prevé una bajada del $15 \%$ de visitantes para el próximo año y, en consecuencia, en recursos propios. Una caída de público que se percibiría por primera vez, desde hace mucho tiempo, en el Museo del Prado. Sobre ello véase, Peio H. Riaño (6/2/2013): "El Prado sube un 15\% su entrada para evitar el cierre y Zugaza prevé una caída de visitantes". El Confidencial.com

[15] En su simposio: Hacia una nueva institución, junto con otros agentes culturales (curadores, historiadores del arte, etc.), en los Encuentros sobre Comisariado, impartido por la UNIA, que han tenido lugar el pasado septiembre de 2012 en el Centro Andaluz de Arte Contemporáneo (CAAC).

[16] Cuestiones relacionadas con lo regional y lo global, en concordancia con temas abordados últimamente por el ICOFOM: con la Diversidad, con la Memoria, con lo Intangible, con el Desarrollo social y sobre todo con la Ética, como programa filosófico de la nueva Museología. Léase: André 
Devallés. Muséologie, Patrimoine, changement économique et developpment social. ICOFOM Study Series-ISS 33a.

[17] A modo de ejemplo, el pasado día 1 de Marzo de 2013 se inauguró el Museo de Arte de Río de Janeiro (MAR), un museo construido en una antigua comisaría de policía de la dictadura brasileña. Además de contener ya una colección de 3.000 piezas con 50 donantes, alternando espacios para exposiciones de arte contemporáneo y otras de colecciones privadas o temáticas, se dedica principalmente a la formación continua de profesores y alumnos de barrios deprimidos (El País, 7-32013: 47)

[18] En torno a ello un clásico es el estudio de Pierre Bourdieu, L'amour de l'art. Les musées d'art européens et leur public (1969).

[19] Tal y como expresa Anna M. Guasch: "Crisis de financiación, crisis de audiencias, crisis de significado, crisis de legitimación política, crisis de arte de vanguardia, crisis de arquitectura y crisis de mercado" (Guasch 2008: 10-12).

\section{Bibliografía}

ADORNO, T. W. (1962). "Valéry Proust Museum". Prismas. La crítica de la cultura y la sociedad. Barcelona: Ariel, 187.

ADORNO, T. y HORKHEIMER, M. (1998) (1944). Dialéctica de la llustración. Fragmentos filosóficos. Madrid. Trotta.

AMEndolA, G. (2000). La Ciudad Postmoderna. Magia y Miedo de la Metrópolis Contemporánea, Madrid: Celeste, 183-209.

BADIA, M. (2011). "El comisariado en crisis. Notas a partir de los modelos curatoriales de Manifiesta". A*Desk (Critical Thinking). 71. http://www.a-desk.org/spip/spip.php?article882 [Consulta: 12/1/2011]

BALLART, J. (2007). Manual de museos, Madrid: Ed. Síntesis.

BARÓN F. (2013). "De la sala de tortura a la sala de arte". El País-Cultura, 47.

BARTHES, R. (2009) (1a ed. París, 1984). "La muerte del autor" (1968), en el Susurro del Lenguaje. Más allá de la palabra y la escritura, Barcelona: Paidós, 75-84.

BENJAMIN, W. (1973) (1a ed. alemana, 1972). "La obra de arte en la época de su reproductibilidad técnica" (1936) en Discursos Interrupidos I. Madrid: Taurus.

BOURDIEU, P. (2003) (1969). El amor al arte. Los museos europeos y su público, Barcelona: Paidós.

BOURRIAUD, N. (2008 3aed.) (1998). Estética Relacional, Buenos Aires: Adriana Hidalgo, 6-8.

CARRILLO, J. (2008). “Las nuevas fábricas de la cultura: los lugares de la creación y la producción cultural en la España contemporánea".

http://www.anticteatre.com/mov_8octubre/J.Carrillo_nuevas_fabricas_de_la_cultura.pdf [Consulta: 9/12/2012]

CARRILLO, J. (2012): "Hacia una nueva institución". Simposio en el encuentro sobre Introducción al Comisariado, Sevilla: UNIA Y Centro Andaluz de Arte Contemporáneo (CAAC).

CARRILLO, J. (2012). “Las instituciones culturales y la reformulación del espacio público”. Conferencia en XXIII Sesión del VI Curso de Introducción al Arte Contemporáneo 2011-2012, MUSAC. En línea: https://vimeo.com/43113771 [Consulta: 24/1/2013].

CHAGAS, M. (2009-10). "Los museos en el marco de la crisis", revista Museos.es, 5-6: 86101.http://es.calameo.com/read/000075335586d490a82c6 [Consulta: 8/10/2012]

COLLERA, V. (2011). “La burbuja de los museos”, El País-Babelia, 18. 
CRIMP, D. (2005). "Sobre las ruinas del museo" (October 1980), enPosiciones críticas. Ensayos sobre las políticas de arte y la identidad, Madrid: Akal, 61-72. El mismo texto aparece también publicado en español en: FOSTER, H. (1998) (1983): La Postmodernidad. Barcelona: Kairón, 75-92.

DEVALLES, A.. Muséologie, Patrimoine, changement économique et developpment social. ICOFOM Study Series ISS $33^{\mathrm{a}}$.

DOUGLAS, D. (1990). The Museum Transformed: Design and Culture in the Post-Pompidou Age. New York: Abbeville Press Publishers, 16.

ESPEJO B. (2012). "por dónde pasa el futuro del comisariado?", El Cultural.es.

http://www.elcultural.es/version_papel/ARTE/31299/Por_donde_pasa_el_futuro_del_comisario [Consulta: 6/7/2012]

GIEBELHAUSEN, M. (2011). "The architecture is the museum". EnNew Museum Theory and Practice: an introduction, Marstine, J. (ed.). USA: Blaclwell Publishing, 41-63.

GUASCH, A. M. y ZULAIKA, J. (2007). Aprendiendo del Guggenheim de Bilbao. Madrid: Akal, 13.

GUASCH, A. M. (2008). "Los museos y lo museal". Revista Calle 14. 2. Universidad de Barcelona. 10-22. http://annamariaguasch.net/pdf/MUSEOS_LO_MUSEAL.pdf [Consulta: 17/9/2011]

GUASCH, A. M. (2009). El arte del siglo XX en sus exposiciones, 1945-2007, Barcelona: Ed. Serbal.

GUASCH, A. M. (2011). Arte y Archivo, 1920-2010, Madrid: Akal, 42.

HUYSSEN, A. (2002). En busca del futuro perdido: Cultura y memoria en tiempos de globalización, Buenos Aires: Fondo de Cultura Económica y Goethe Institut.

KING, L., y MARSTINE, J. (2011) (2006). "The University Museum and Gallery: A site for institutional critique and a focus of the curriculum" en New Museum Theory and Practice: an introduction, USA: Blaclwell Publishing, 266-291.

KRAUSS, R. (1995). "La lógica cultural del museo tardocapitalista", Museos de Vanguardia, Monografías de Arquitectura y Vivienda, 39: 25.

KRAUSS, R. (2005). "Postmodernism's Museum without Walls" en Thinking about Exhibitions, Routledge, 241245.

LIPOVETSKY, G. (2003). La era del vacío: Ensayos sobre el individualismo contemporáneo, Madrid: Anagrama.

LÓPEZ, J. R. (2010). Historia de los museos de Andalucía 1500-2000, Universidad de Sevilla: Secretariado de Publicaciones, 538.

LOSADA, J. C. (2010). Comunicación en la gestión de crisis, Barcelona: Editorial UOC, 21.

MALRAUX, A. (1965) (1947).Le musée imaginaire. París, Gallimard.

MANEN, M. (2012): Salir de la Exposición (si es que alguna vez habíamos entrado), Bilbao, Consonni, 100.

MEIJERS, D. (1996). "The Museum and the 'ahistorical' exhibition", Thinking about exhibitions, Londres: Routlege, 5-14.

MONTANER, J.M. (2003). Museos para el Siglo XXI. Barcelona: Gustavo Gili.

OBRIST, H. U. (2009). "When Attitudes Become Form de Harald Szeemann. (Los hitos del arte. 1969: el papel del comisario)", El Cultural.es

http://www.elcultural.es/version_papel/ARTE/26005/When_Attitudes_Become_Form_de_Harald_Szeemann [Consulta: 16/10/2009].

OBRIST, H. U. (2010) (2008). Breve historia del comisariado, Madrid: Exit publicaciones.

O'DOHERTY, B. (1999) (1976). Inside the White Cube. The ideology of the Gallery Space. Berkeley, Los Ángeles, Londres: University of California Press. 
RENDUELES, C. (2012). "¿Quiénes deciden el valor real de las obras de arte?", El Confidencial. http://www.elconfidencial.com/alma-corazon-vida/2012/02/18/quienes-deciden-el-valor-real-de-las-obrasde-arte-92816/ [Consulta: 18/2/2012].

RIAÑO, P. H., (6/2/2013). “El Prado sube un 15\% su entrada para evitar el cierre y Zugaza prevé una caída de visitantes". El Confidencial.

http://www.elconfidencial.com/cultura/2013/02/06/el-prado-sube-un-15-su-entrada-para-evitar-el-cierre-yzugaza-preve-una-caida-de-visitantes-114390/ [Consulta: 6/2/2012].

Site del MUSAC (2013). "Misión del Museo": http://musac.es/index.php?secc=1\&subsecc=1 [Consulta: $11 / 1 / 2013]$

VILLEL, M. B. (2012). "Atención: riesgo de amnesia", El País Cultura.http://cultura.elpais.com/tag/arte/a/ [Consulta: 19/10/2012].

VOZMEDIANO E. (2007). "Hans Ulrich Obrist: Hoy todo es grande, pero creo que el modelo macro-exposición se está hundiendo". El Cultura.es

http://www.elcultural.es/version_papel/ARTE/21755/Hans_Ulrich_Obrist/ [Consulta: 22/11/2007].

VV.AA. (2009). 10.000 francos de recompensa. El museo vivo o muerto, Barcelona: ADACE, SEACEX, UNIA (ed).

VV.AA. (2013). "Los profesionales de los museos dan la voz de alarma sobre su precariedad". El Confidencial. http://www.elconfidencial.com/cultura/2013/03/26/ [Consulta: 26-03-13].

ZULAIKA, J. (1997). Crónica de una seducción: el museo Guggenheim de Bilbao, Hondarribia, Nerea.

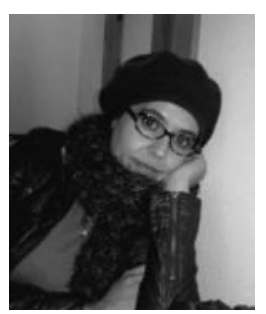

Susana Solís Zara

s.soliszara@gmail.com

http://susanasoliszara.virtualgallery.com

Es Licenciada en Bellas Artes por la Universidad de Sevilla. Centro en el que obtuvo el Diploma de Suficiencia Investigadora (DEA) y donde, en la actualidad, realiza su tesis doctoral (de contenido vinculado al presente artículo), conjugando su labor de investigadora con la práctica artística gráfico-plástica.

También es miembro del grupo de investigación HUM 552: Artana (Plástica y Arte Anatómico), adscrito al Departamento de Dibujo, perteneciente a la línea de investigación plástica y gráfica.

Artículo envío el 04/03/2013

Artículo aceptado el 13/05/2013 